\title{
Modeled Oceanic Response and Sea Surface Cooling to Typhoon Kai-Tak
}

\author{
Yu-Heng Tseng ${ }^{1, *}$, Sen Jan ${ }^{2}$, David E. Dietrich ${ }^{3}$, I-I Lin ${ }^{1}$, Ya-Ting Chang ${ }^{4}$, \\ and Tswen-Yung Tang ${ }^{4}$ \\ ${ }^{1}$ Department of Atmospheric Sciences, National Taiwan University, Taipei 10617, Taiwan, ROC \\ ${ }^{2}$ Institute of Hydrological and Oceanic Sciences, National Central University, Jhongli 32001, Taiwan, ROC \\ ${ }^{3}$ AcuSea Inc., 8450-101 Via Sonoma, La Jolla, CA92037, USA \\ ${ }^{4}$ Institute of Oceanography, National Taiwan University, Taipei 10617, Taiwan, ROC
}

Received 4 June 2009, accepted 8 June 2009

\begin{abstract}
An ocean response to typhoon Kai-Tak is simulated using an accurate fourth-order, basin-scale ocean model. The surface winds of typhoon Kai-Tak were obtained from QuikSCAT satellite images blended with the ECMWF wind fields. An intense nonlinear mesoscale eddy is generated in the northeast South China Sea (SCS) with a Rossby number of O(1) and on a 50 $100 \mathrm{~km}$ horizontal scale. Inertial oscillation is clearly observed. Advection dominates as a strong wind shear drives the mixed layer flows outward, away from the typhoon center, thus forcing upwelling from deep levels with a high upwelling velocity $\left(>30 \mathrm{~m} \mathrm{day}^{-1}\right)$. A drop in sea surface temperature (SST) of more than $9^{\circ} \mathrm{C}$ is found in both observation and simulation. We attribute this significant SST drop to the influence of the slow moving typhoon, initial stratification and bathymetry-induced upwelling in the northeast of the SCS where the typhoon hovered.
\end{abstract}

Key words: Air-sea interaction, Typhoon, Upwelling

Citation: Tseng, Y. H., S. Jan, D. E. Dietrich, I. I. Lin, Y. T. Chang, and T. Y. Tang, 2010: Modeled oceanic response and sea surface cooling to typhoon Kai-Tak. Terr. Atmos. Ocean. Sci., 21, 85-98, doi: 10.3319/TAO.2009.06.08.02(IWNOP)

\section{INTRODUCTION}

It is well known that tropical cyclones (TCs), also known as typhoons (in the Pacific) and hurricanes (in the Atlantic), draw their energy from warm ocean waters (Emanuel et al. 1986). Through air-sea interaction, the ocean supplies energy for a typhoon's intensification (Emanuel et al. 1986; Moon et al. 2007, 2008; Lin et al. 2009a). Pre-existing ocean mesoscale features and subsurface structures may be far more important than sea surface temperature (SST) alone in the heat and moisture fluxes feeding the storm. Shay et al. (2000) noted an abrupt change in the intensity of hurricane Opal $(9 / 28-10 / 5,1995)$ when it passed over a large warm core eddy (WCE). Hurricane Katrina in August 2005 also showed a very similar intensification while passing over the Loop Current and WCE regions. Lin et al. $(2005,2008)$ noted the critical role of warm ocean eddies in the western North Pacific category-5 typhoons in observing that $30 \%$ of these super typhoons are fuelled by warm ocean

\footnotetext{
* Corresponding author

E-mail: yhtseng@as.ntu.edu.tw
}

features. Wu et al. (2007) used a simple coupled typhoonocean model to study the role of warm and cold eddies in a typhoon's intensification. Typhoons also cause significant SST cooling which provides negative feedback to the overlying storm by reducing the latent and sensible heat sources to the eye wall region. For example, satellite images showed that SST dropped more than 9 and $11^{\circ} \mathrm{C}$ in response to the passage of typhoons Kai-Tak (Lin et al. 2003) and LingLing (Shang et al. 2008), respectively. Wu et al. (2008) studied the air-sea interaction between typhoon Nari and the Kuroshio current using satellite observations and an ocean model. The intensity of typhoon Nari varied a few times when it crossed over the Kuroshio current. These examples demonstrated the role of warm (and cold) oceanic features in providing a positive (as well as negative) feedback to the overlying storms by causing an intensification (or weakening) of the storms.

In general, the primary mechanisms accounting for sea surface cooling caused by TCs include mixed layer depth (vertical mixing/entrainment) and thermocline depth, an exchange of air-sea heat fluxes, and the storm's intensity 
and translation speed (Price 1981; Lin et al. 2009b). Intense, slow moving typhoons usually cause a larger SST response. Since evaporation due to high winds over warm water sustains the thermodynamic cycle of a TC, SST cooling is thought to inhibit cyclone intensification, preventing the cyclones from attaining their full intensity potential (Emanuel $1999,2001)$. When a typhoon encounters warm ocean features, SST cooling may be greatly suppressed primarily due to deep mixed-layer and thermocline (Wu et al. 2008).

Early studies of upper-ocean response to TCs include field observations (e.g., Shay et al. 1989; Jacob et al. 2000) and three-dimensional numerical ocean or coupled models (Price 1981; Price et al. 1994; Cubukcu et al. 2000). Recent studies emphasized the understanding of the dynamic processes and interactions with the atmosphere, ocean heat content and ocean currents (e.g., Oey et al. 2007; Sheng et al. 2007; Tsai et al. 2008; Wu et al. 2008). Typically, the ocean's response to TCs can be divided into two stages: forced and relaxation stages. During the forced stage, the hurricane winds drive the mixed layer currents, causing SST cooling by vertical mixing (entrainment) and air-sea heat exchange (e.g., loss of latent heat flux). The barotropic response consists of a non-geostrophic component which changes the sea surface height (a part of the inertia gravity response). The relaxation stage response follows a hurricane's passage, and is primarily influenced by inertial gravity oscillations excited by the TC. The mixed-layer velocity oscillates with a near-inertial period, and hence so does the divergence and the associated upwelling and downwelling (Tsai et al. 2008).

However, no study has focused on the causes and mechanisms of the significant temperature drops for particular TCs. Oceanic responses to TCs differ from one to another in several respects, and thereby make the processes difficult to study. This is further complicated by pre-existing oceanic features that modulate the upper ocean heat, mass and momentum balance due to advection. These mesoscale features need to be resolved in order to study the oceanic response. The extremely large amount of surface cooling in typhoon Kai-Tak was found mainly because of the continuous wind forced upwelling, a relatively shallow and warm mixed layer in the SCS and the local bathymetry of the SCS. The upwelling was enhanced by the typhoon's quasistationary motion. Similarly, a shallow mixed layer depth $(\sim 30 \mathrm{~m})$ was also observed in the case of typhoon Ling-Ling and may have contributed to the $11^{\circ} \mathrm{C}$ temperature drop after its passage (Shang et al. 2008). The coastal upwelling and pre-existing ocean features significantly enhanced pronounced sea surface cooling.

The main objectives of this paper are (1) to study the effect of a slow moving typhoon (Kai-Tak) in the South China Sea; (2) to quantify the physical processes which control the upper ocean thermal structure and strong surface cooling during the typhoon's passage; and (3) to assess the model's ability to reproduce the observed behavior of the oceanic responses to a typhoon without data assimilation. This paper is organized as follows: section 2 describes the passage of typhoon Kai-Tak and relevant observations. Section 3 details the model configuration, initial and boundary conditions and model experiments. Section 4 compares the simulated results with observations followed by a qualitative description of the oceanic response to typhoon Kai-Tak. The mechanism that causes the significant SST drop is also investigated. The summary and conclusion are given in section 5 .

\section{TYPHOON KAI-TAK AND OBSERVATIONS}

Typhoon Kai-Tak was declared a category 2 TC on the Saffir-Simpson hurricane scale. It lingered with slow speeds $\left(0-1.4 \mathrm{~m} \mathrm{~s}^{-1}\right)$ in the northern SCS from July $5-8$, 2000 before moving rapidly northward thereafter (see Fig. 1 for the storm track). The typhoon remained almost at rest during July $6-8$. Remote sensed data provided an opportunity to investigate the surface behavior. Two remote sensed datasets were used in an earlier study (Lin et al. 2003); QuikSCAT and the Tropical Rainfall Measuring Mission (TRMM) Microwave Imager (TMI), respectively. The ocean surface wind vector (QuikSCAT) and the sea surface temperature (TMI) were measured day and night under both clear and cloudy conditions. The cloud penetrating capability of TMI allows the entire area of entrainment (location of a phytoplankton bloom patch) to be sensed. Here we have also incorporated QuikSCAT to provide an adequate wind forcing information in the model simulation. Figure 2 shows the averaged daily wind fields taken from QuikSCAT, illustrating how the typhoon lingered for several days in the northeast SCS during its passage of the SCS. More details about the wind forcing are provided in the next section.

Before typhoon Kai-Tak's arrival, the SCS was characterized by predominantly warm SST greater than $30^{\circ} \mathrm{C}$ (Lin et al. 2003). Based on an average of ten-day TOPEX/Poseidon (T/P) satellite images, the Sea Surface Height Anomaly (SSHA) showed relatively calm eddy fields in the northeast SCS prior to July 5 (Fig. 1a). The typhoon's strong winds $\left(20-40 \mathrm{~m} \mathrm{~s}^{-1}\right)$ dominated the QuikSCAT wind field during July 7 to July 8 (Fig. 2). Immediately after typhoon Kai-Tak's departure, a cold SST pool, with temperatures of $21.5-24^{\circ} \mathrm{C}\left(118-120^{\circ} \mathrm{E}, 19-20.5^{\circ} \mathrm{N}\right)$ of a size comparable to Kai-Tak's $150 \mathrm{~km}$ RMW (Radius of Maximum Wind), was observed and co-located with the typhoon's track. The minimum SST of $21.5^{\circ} \mathrm{C}$ was found at the center $\left(118.9^{\circ} \mathrm{E}\right.$, $19.9^{\circ} \mathrm{N}$ ) of the cold pool (Lin et al. 2003). In comparison with pre-typhoon conditions, the SST had dropped by as much as $8-9^{\circ} \mathrm{C}$. This cold pool slowly decayed after the passage of the typhoon, but still maintained a low temperature of $25^{\circ} \mathrm{C}$. After the passage of typhoon Kai-Tak, the formation of a cyclonic eddy was observed, which is clearly intensified in the T/P image in Fig. 1b. The location, scale and peak of 
(a)

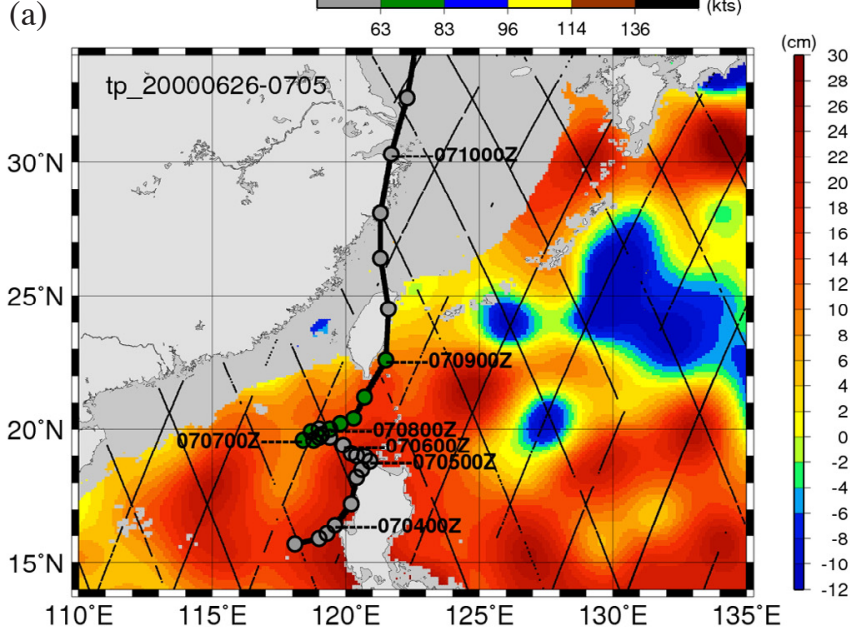

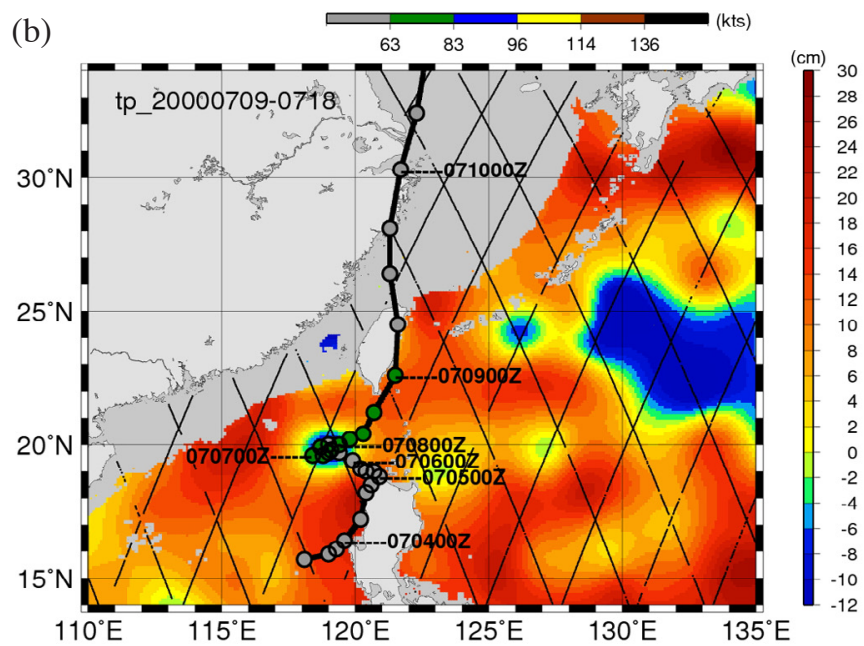

Fig. 1. Ten-day averaged SSHA images from the TOPEX/Poseidon satellite altimeter before and after typhoon Kai-Tak's passing in the northeast South China Sea [June 26 - July 5 (a) and July 9 - 18 (b), respectively]. The Luzon Strait is between Taiwan and Philippine. The storm-track of typhoon Kai-Tak is superimposed.
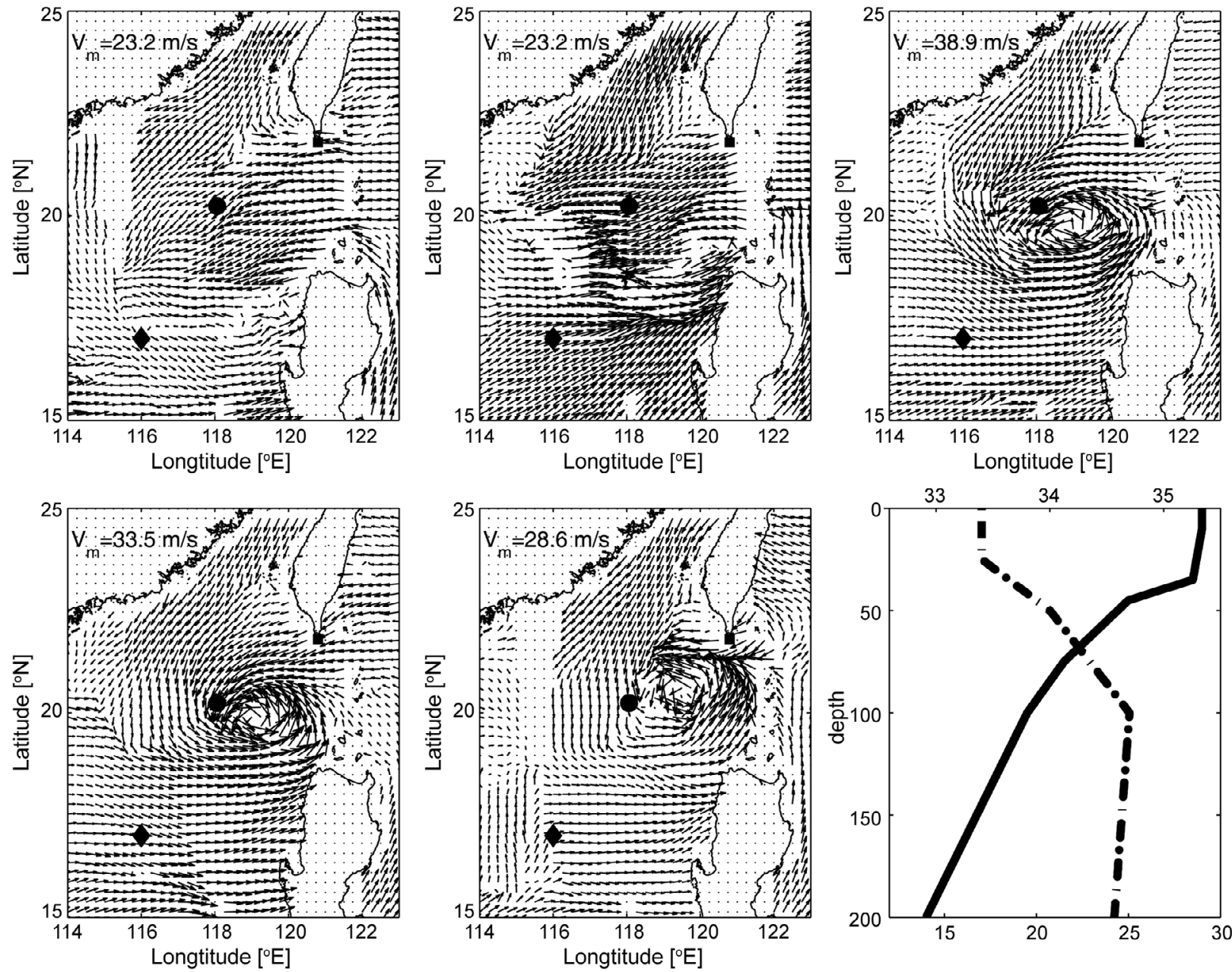

Fig. 2. Daily averaged QuikSCAT wind fields at $10 \mathrm{~m}$ from 2000/7/3 (top left) to 2000/7/7 (bottom center). The initial stratification (temperature and salinity) is shown in the bottom right panel, taken from the nearby SEAT station before the passage of Typhoon Kai-Tak. Observational stations:

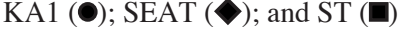


the growing cyclonic eddy (Fig. 1b) matched well with the cold SST pool shown in Lin et al. (2003). The cyclonic eddy lasted for more than two weeks (Fig. 1b). From these satellite images, the westward propagating Rossby waves and eddy fields in the North Pacific Ocean were identified while the cyclonic eddy grew in the northeast SCS.

Some in-situ hydrographic surveys were conducted in the northeast SCS during the year 2000, including the South East Asia Time-series (SEATS) station $\left(116^{\circ} \mathrm{E}\right.$, $18^{\circ} \mathrm{N}$ ) in July 2000 and the Kuroshio Upstream Dynamics Experiment (KUDEX) mooring station KA1, labeled as a circle "•" in Fig. 2 (see Table 1 for detailed information). Both stations were under the influence of typhoon Kai-Tak. Some comparison with station KA1 will be discussed in section 4. The initial stratification taken from the SEATS station (diamond, " $\bullet$ ") is shown in Fig. 2. The mixed surface layer, with a temperature of $29^{\circ} \mathrm{C}$, was only about $20-30 \mathrm{~m}$ deep (Fig. 2 bottom right). After the passage of typhoon Kai-Tak, the minimum temperature in the cold pool dropped to $21.6^{\circ} \mathrm{C}$, which corresponded to the initial temperature at $71 \mathrm{~m}$ depth. The other station used in the comparison is an observation station at the southern tip of Taiwan (ST, labeled as a square "⿴囗" in Fig. 2).

\section{NUMERICAL SIMULATIONS}

\subsection{Model Setup and Description}

The Dual grid Pacific Ocean Model (DUPOM) used herein is based on an accurate fourth-order, collocated Arakawa-A grid DieCAST (Dietrich/Center for Air Sea Technology) model (Dietrich 1997; Dietrich et al. 2004a; Tseng et al. 2005; Tseng and Breaker 2007). The control volume equations include fluxes of the conservation properties (momentum, heat and salt) across control volume faces. The model domain covers the entire North Pacific Ocean, ranging from $30^{\circ} \mathrm{S}$ to $60^{\circ} \mathrm{N}$ and from $100^{\circ} \mathrm{E}$ to $80^{\circ} \mathrm{W}$. To reduce the computational time, a dual grid approach was adopted based on a multiple grid framework, which uses higher resolutions to resolve eddies more realistically (Dietrich et al. 2004a; Dietrich et al. 2008). A $1 / 8^{\circ}$ resolution was used west of $150^{\circ} \mathrm{E}$, where a finer resolution was required to resolve the detailed Kuroshio Current and regional circulations, and a $1 / 4^{\circ}$ resolution was used east of $150^{\circ} \mathrm{E}$ (Fig. 3). The grids are fully two-way coupled at each coarser time step (time steps differ for the two grids) with a single coarse grid overlapping (i.e., $2 \times 2$ in fine grid cells). The meander and eddy exchanges are seamless at the interface without in-

Table 1. KUDEX station KA1.

\begin{tabular}{cccccc}
\hline Station & Location & Sampling interval & Local depth & Data type & Depth (m) \\
\hline \multirow{2}{*}{ KA1 } & $118^{\circ} 06^{\prime} \mathrm{E}, 20^{\circ} 23^{\prime} \mathrm{N}$ & $60 \mathrm{~min}$ & $2885 \mathrm{~m}$ & ADCP & $30-210-10$ \\
\hline
\end{tabular}

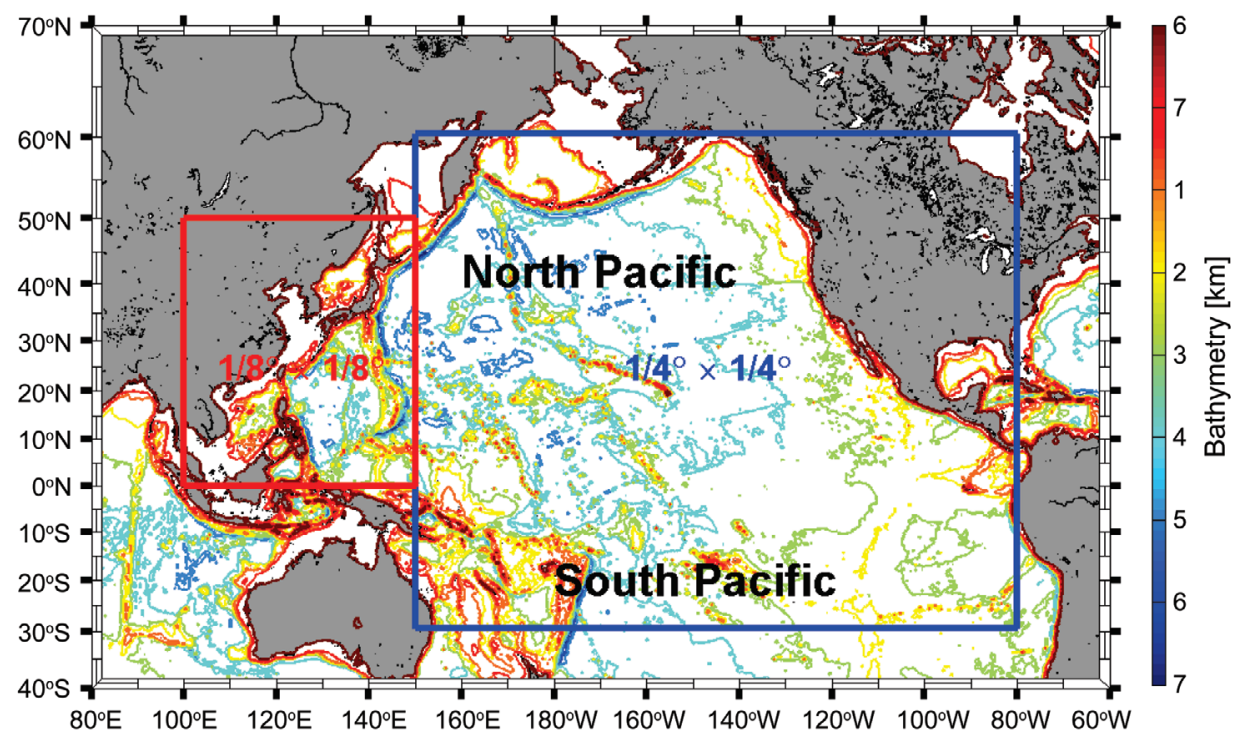

Fig. 3. The dual-grid Pacific Ocean Model, DUPOM, uses two grids in order to resolve critical features in Asia Marginal Sea, such as the Luzon Strait. 
ter-grid sponge layers or special treatments. Further details about the multiple grid approach can be found in Dietrich et al. (2008). Model bathymetry was interpolated from unfiltered ETOPO2 depth data, supplemented with the Taiwan National Center for Ocean Research 1 minute depth archive for the Asian seas. The vertical resolution is linear-exponentially stretched by 26 layers, with a $6-m$ thick top layer. Both grids share the same vertical grid. Within each grid, longitudinal resolution is uniform and latitudinal resolution is generated in such a manner that varying latitude and longitude grid increments are equal everywhere (Mercator grid).

The surface wind forcing in the basic model is obtained from the interpolated monthly Hellerman and Rosenstein winds (Hellerman and Rosenstein 1983). The Levitus' 94 climatology (Levitus and Boyer 1994) is used to initialize the model and to determine its surface sources of heat and fresh water (E-P) using the non-damping approach described in Dietrich et al. (2004b). The northern boundary is closed and the southern boundary condition $\left(30^{\circ} \mathrm{S}\right)$ is slowly nudging toward climatology in a sponge layer. The bottom is insulated, with non slip conditions parameterized by a nonlinear bottom drag.

Simulation of mixed layer deepening and cooling during the typhoon's passage depends strongly on the choice of vertical mixing scheme. Except for vertical mixing parameters, the present model is very similar to the DieCAST model adaptation used to simulate the response to Hurricane Katrina (Dietrich et al. 2007). Recent studies of upper ocean response to hurricanes, based on several bulk mixed layer entrainment schemes, have revealed significant differences in the heat and mass budgets (Jacob et al. 2000; Jacob and Shay 2003; Prasad and Hogan 2007). The suitability of any particular scheme is still subject to debate. Except for sub-grid scale vertical mixing parameters, the present model is very similar to that used by Sheng et al. (2006) and by Dietrich et al. (2008). The model's sub-grid scale vertical mixing is parameterized by eddy diffusivity (for temperature and salinity) and viscosity (for momentum) using a modified Price (1981) scheme as described in Sheng et al. (2006). This new scheme, replacing the default Pacanowski and Philander (1981) scheme, was chosen to obtain a better mixed layer due to the strong wind forcing during the passage of the typhoon. Background lateral viscosity and diffusivity are 100 and $200 \mathrm{~m}^{2} \mathrm{~s}^{-1}$, respectively.

\subsection{Initial and Boundary Conditions}

This study emphasizes dynamic processes rather than the model's capability of nowcasting or forecasting. The model approached a quasi-equilibrium status after a few years of spinning up. The circulation pattern on July 1 of model year 23 was then chosen as the initial condition for the simulation of typhoon Kai-Tak. Initial temperature and salinity fields are based on the SEATS observations before typhoon Kai-Tak's passage in July 2000. All model integrations were started on July 3, 2000 (see Fig. 1 for the typhoon's track).

The model was then driven by fields of $10 \mathrm{~m}$ wind stress extracted from six-hourly $2.5^{\circ}$ ERA40. It is well known that the ERA-40 product does not adequately resolve TCs. In this study, we further blended the ERA-40 winds with the QuikSCAT analyzed winds (Fig. 2). Since the QuikSCAT data (twice per day) provided a more realistic and high quality wind field and may not be consistent with the ERA-40, a smoothing procedure was performed. We took the difference between the QuikSCAT and ERA-40 winds at each of the discrete observations and times. This difference was merged into an "extended winds window" (EWW) grid, which was larger than the localized QuikSCAT wind field. The difference was then set to zero at the boundary of EWW, followed by a Poisson spreader to spread the difference between the QuikSCAT wind and the EWW grid boundaries. In order to minimize the nudging at the EWW grid boundaries, the EWW should extend laterally at least an eddy size beyond the QuikSCAT wind fields. Finally, the blended wind fields were then interpolated back to the model domain for application.

Following Oey et al. (2006), the wind stress was calculated from the wind fields using a bulk formula:

$$
\begin{aligned}
\mathrm{C}_{\mathrm{d}}= & 0.0012, \quad\left|\mathrm{u}_{\mathrm{a}}\right| \leq 11 \mathrm{~m} \mathrm{~s}^{-1} \\
= & 0.00049+0.000065\left|\mathrm{u}_{\mathrm{a}}\right|, \quad 11<\left|\mathrm{u}_{\mathrm{a}}\right| \leq 19 \mathrm{~m} \mathrm{~s}^{-1} \\
= & 0.001364+2.34 \times 10^{-5}\left|\mathrm{u}_{\mathrm{a}}\right| \\
& -2.3 \times 10^{-7}\left|\mathrm{u}_{\mathrm{a}}\right|^{2}, \quad 19<\left|\mathrm{u}_{\mathrm{a}}\right|<100 \mathrm{~m} \mathrm{~s}^{-1}
\end{aligned}
$$

where $\left|\mathrm{u}_{\mathrm{a}}\right|$ is wind speed (the maximum wind speed reached $\sim 40 \mathrm{~m} \mathrm{~s}^{-1}$ from the QuikSCAT). This formula modifies Large and Pond (1981) to incorporate the limited drag coefficient for high wind speeds (Powell et al. 2003). All wind stresses were assumed to be in dynes $\mathrm{cm}^{-2}$ and of a magnitude less than 100 dynes $\mathrm{cm}^{-2}$.

\section{NUMERICAL RESULTS}

\subsection{Typhoon-Induced Circulation and Inertial Currents during Typhoon Kai-Tak}

Figure 4 shows the equivalent sea surface height (SSH) superimposed by the surface velocity vector for every 30 hours, after imposing the QuikSCAT wind forcing on July 3 . The eyewall winds enhanced a strong, out-of-balance cyclonic flow, as indicated by the vectors which revealed a large outward flow component of the cyclonically spinning water. The wind-induced currents are frictionally driven by the wind, and their pattern generally follows the wind field. After hour 90, the wind driven currents were intensified and concentrated over the northeast SCS (July 6). The intense 

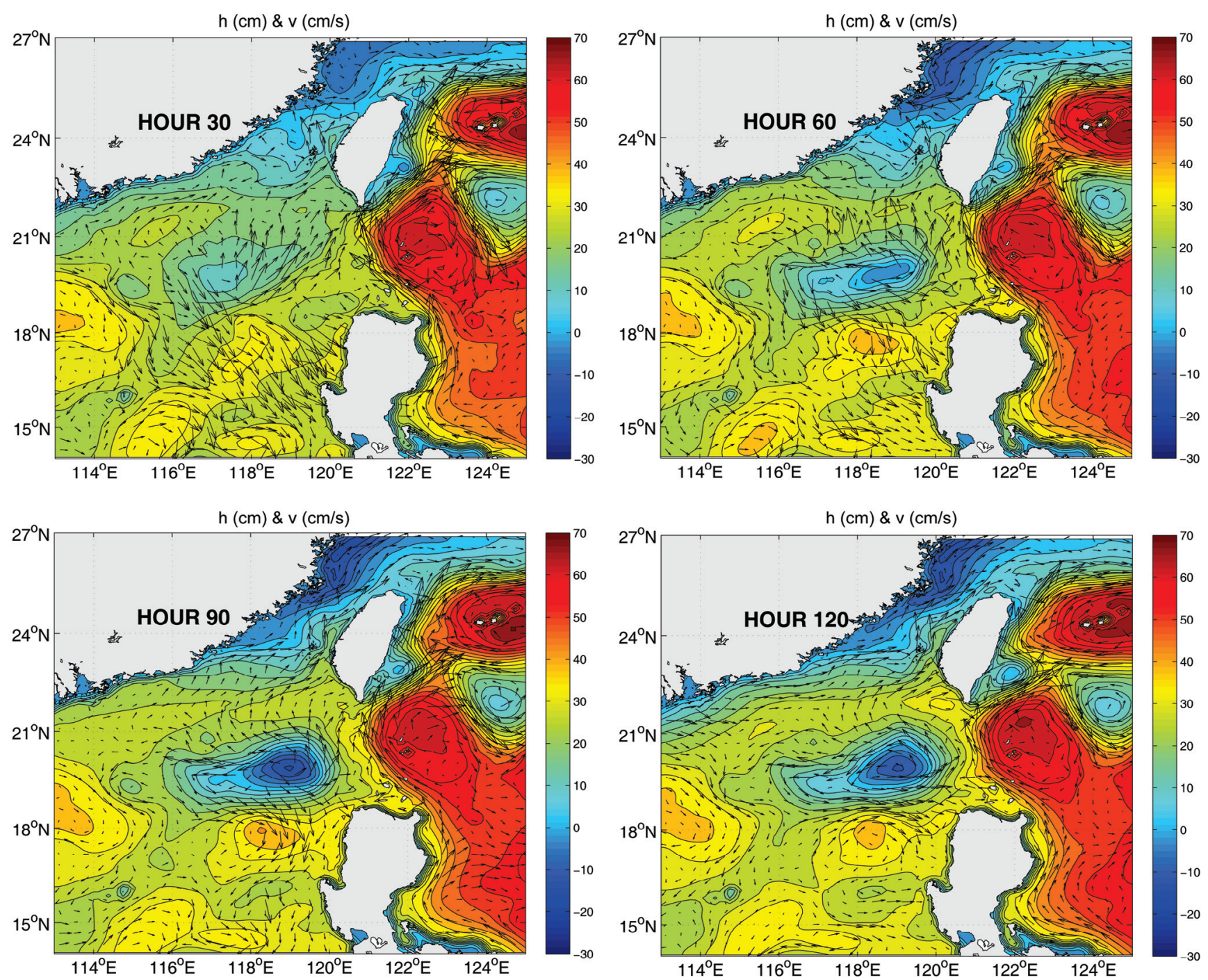

Fig. 4. Simulated surface current velocity and sea surface height ( $\mathrm{SSH})$ at different time.

nonlinear mesoscale vortex has a scale of $\sim 100-150 \mathrm{~km}$. The SSH fields showed that typhoon Kai-Tak hovered over the SCS, and strengthened its cylonic circulation for a few days. The slowly moving typhoon enhanced the cyclonic eddy to penetrate into deeper layers (Wu et al. 2008).

During the passage of typhoons, a sudden change of the surface wind stress can generate inertial motions in the upper ocean (Gill 1982). In the north SCS, the averaged inertial period was about $35 \mathrm{hr}\left(\sim 20^{\circ} \mathrm{N}\right)$. The TC-induced inertial motions can last for two weeks or longer in some cases. We further compared the model velocities with those measured at the ADCP mooring station KA1 (KUDEX). The modeled zonal and meridional velocity ( $\mathrm{U}$ and $\mathrm{V}, \mathrm{cm} \mathrm{s}^{-1}$ ) components were compared with the observed velocity profiles vertically at the same location (Fig. 5). To separate rapidly fluctuating inertial motions from other relatively low frequency inertial currents, a six hour low-pass filter was applied to the observed currents. Figure 5 shows the vertical profile comparison between the modeled and observed velocity components. The sensitivity of turbulent parameterization is also evaluated in the upper two panels. Both model and observation showed reasonable quasi-inertial oscillations $\sim 34 \mathrm{hr}$. The model using the modified Price scheme showed more ordinary patterns, while the KA1 observation presented a larger variability. Using QuikSCAT wind vectors, entrainment-induced mixed layer deepening was estimated at $\sim 100 \mathrm{~m}$ by a modified mixed layer turbulence parameterization (Sheng et al. 2006), and varied with time (Fig. 5). This parameterization appears to perform relatively well compared with the traditional Pacanowski and Philander (1981), denoted by PP82 in the current simulation, due to the larger typhoon-induced vertical mixing and entrainment. The modeled mixed layer was shallower using the PP82 parameterization, resulting from insufficient vertical mixing in the surface mixed layer. More comparison between different turbulent parameterizations is discussed later. 

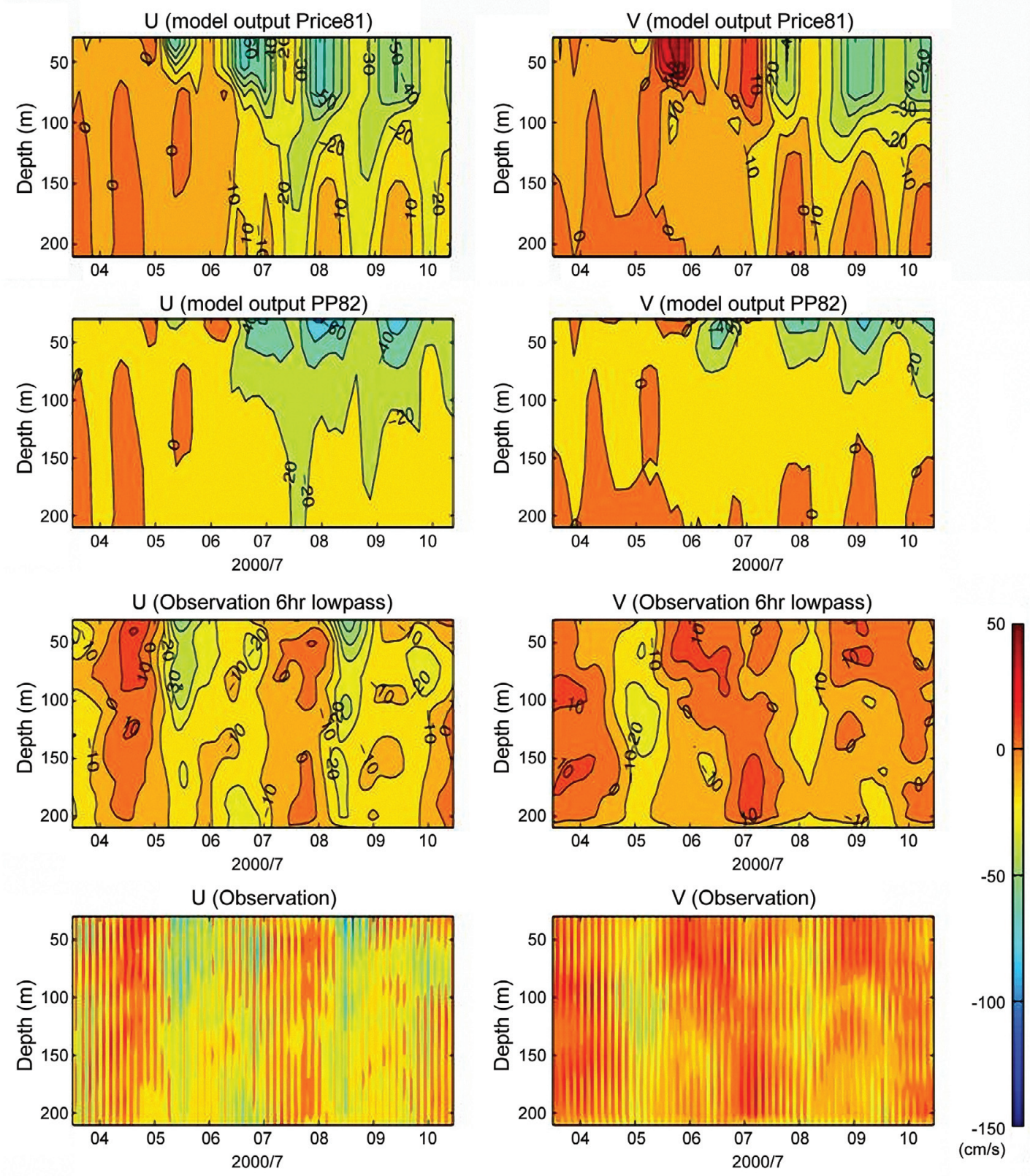

Fig. 5. Comparison of velocity profiles in the upper layer between the DUPOM and observation. Model (top), filtered observation (middle), observed raw data (bottom).

Figure 6 shows additional time series velocity components in the upper layer at four different locations. The relative locations with respect to the typhoon center are west, east, north and south (top to bottom). Large inertial currents were concentrated around the typhoon. The flow velocities also changed directions during the passage of typhoon KaiTak. Unlike the wind-driven currents, the inertial amplitudes in a fast moving typhoon are usually much larger on the right of the typhoon path than on the left. This amplitude asymmetry is particularly striking when the wind vectors rotate at roughly the same rate as the inertial motion (Chang and Anthes 1978; Price 1981). It is found that the amplitude asymmetry is not so clear in Fig. 6 due to the slow movement of typhoon Kai-Tak. It appears that the inertial currents were not destroyed by the quasi-stationary typhoon Kai-Tak. These inertial motions lasted for a long time after typhoon Kai-Tak had passed from the observation region (Chen 2006).

\subsection{Sensitivity of Turbulence Parameterization}

The role of mixing and upwelling was also examined using the observational profiles at ST. ST is a station located at the southern tip of Taiwan (see Fig. 2 for the location). Since typhoon-induced turbulent mixing is difficult to resolve in the ocean model and cannot be easily parameter- 

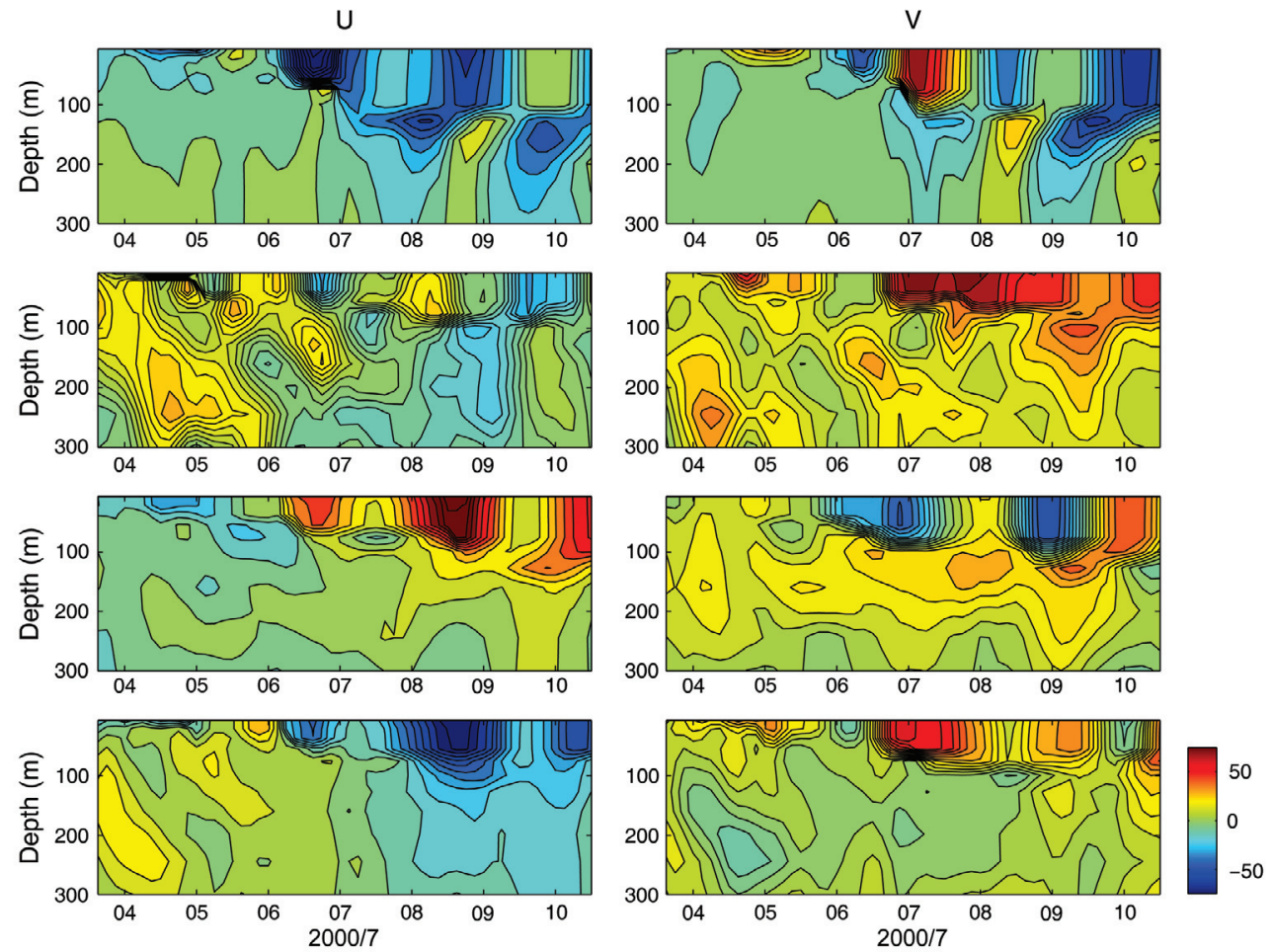

Fig. 6. Time-series velocity components in the upper layer at different locations. Relative locations with respect to typhoon center: west, east, north, south (from top to bottom).

ized, we attempted to further explore the influence of different turbulence parameterizations. Zedler et al. (2002) used four one-dimensional mixed layer models, namely PriceWeller-Pinkel (PWP), K Profile Parameterization (KPP), Mellor-Yamada 2.5 (MY), and a modified version of MY2.5 (MY2), to investigate the upper ocean's response to Hurricane Felix (1995). Temperature evolution was found to be sensitive to the parameterization schemes chosen. They also found that the sea surface cooling predicted by KPP model was closer to the observations than any of the other models. This is partially due to a special treatment for gradient Richardson number shear instability mixing in response to resolved shear in the ocean interior (Zedler et al. 2002).

The results of our model experiments are presented in Fig. 7a. The impacts of turbulent parameterization were assessed by comparing SSTs, which showed significantly different behaviors after July 5 when strong wind forcing took place. Both PP82 and the modified Price scheme were examined. Similar to the observation, the modeled SST using the modified Price scheme indicated two periods of cooling. The cooling during the storm was primarily due to the strong wind-driven turbulent mixing resulting from vigorous wind stress. It should be noted here that the mixing generated by typhoon-induced internal waves is still not well represented in any turbulent parameterization. Further cooling was possibly due to advection, upwelling and further mixing. Apparently, the second period of cooling was missing in the case using the PP82. This difference was not surprising, based on the different mixed layer depths. This implied that the simple Richardson number based PP82 scheme provided insufficient instability mixing and was consistent with the weaker and shallower inertial oscillation response shown in Fig. 5.

Our results supported the importance of realistic parameterization of turbulence in modeling ocean response to tropical cyclones. The temperature evolution is most sensitive to the turbulent mixing parameterization. The greater wind stress, resulting from typhoon Kai-Tak in particular, may have affected the surface mixed layer responses including internal gravity waves, mixed layer deepening and energy redistribution (Zedler et al. 2002). These features could be altered significantly due to different mixing parameterization. Unfortunately, to the best of our knowledge, no ideal turbulent mixing parameterization is currently available for all circumstances. Recent studies also showed that numerical dissipation and diffusion may interact with turbulence schemes unless higher order, non-dissipative numerical methods are used (e.g., Tseng and Dietrich 2006; Tseng 2008).

\subsection{What Caused the Significant Temperature Drop during the Passage of Typhoon Kai-Tak?}

A cool wake is usually a pronounced feature of a moving typhoon, and is significantly biased to the right side of the typhoon track (looking in the direction of the typhoon 
(a)

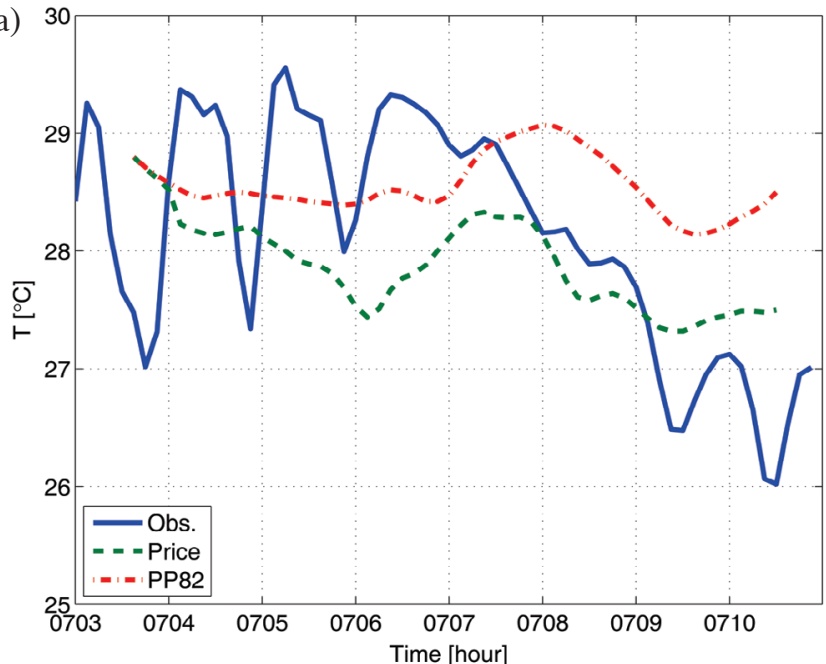

(b)

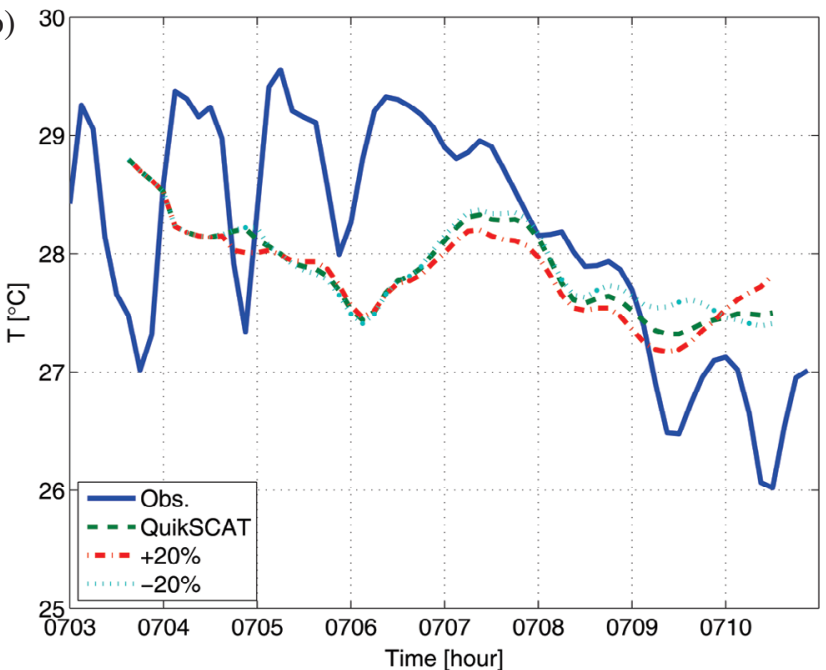

Fig. 7. (a) Comparison of time-series surface temperature between different turbulent parameterization schemes at the south tip of Taiwan. (b) Comparison of time-series surface temperature between different wind stress intensity at the south tip of Taiwan.

motion). This rightward bias of cooling has been attributed to the asymmetric turning (in time) of wind stress that arises from the translation of a vertical wind pattern (Price 1981). For a slowly moving (or quasi-stationary) tropical cyclone such as typhoon Kai-Tak, the rightward bias is less pronounced (Lin et al. 2003), but a cool pool is still evident. Two extreme surface cooling events after the passage of typhoons (including typhoon Kai-Tak) are known to have occurred $\left(>9^{\circ} \mathrm{C}\right.$ ) in the SCS (Lin et al. 2003; Shang et al. 2008). How did such a drastic response happen? Why did these two events of extreme SST cooling occur in the SCS?

Figure $8 \mathrm{a}$ shows the modeled temperature profiles along latitude $20.5^{\circ} \mathrm{N}$ (top) and longitude $119^{\circ} \mathrm{E}$ (bottom) during July $3-8$. The SST started to cool down from July 5 - 7. Consistent with the satellite observations, the overall cool pool temperature dropped to $\sim 22^{\circ} \mathrm{C}$ after July 8 . The cool pool remained there for a few days and no further significant temperature drop was observed following the passage of typhoon Kai-Tak. This suggests that the upwelled thermocline may have reached the ocean surface while the surface layer was well mixed (Figs. 5 - 6). Entrainment mixing is, in general, the primary mechanism accounting for the SST response (Price 1981). However, for a slow moving cyclone (translation speed $\leq 4 \mathrm{~m} \mathrm{~s}^{-1}$ ), such as typhoon KaiTak, strong upwelling occurs with entrainment as a result of the persistent secondary outward near-surface flows, which must occur as part of the geostrophic adjustment during the wind-forced spin-up of an ocean surface cyclonic vortex (Ekman pumping). Thus, the cooling due to surface mixed layer thickening may be significantly enhanced (Price 1981). Figure 8b shows the horizontal distribution of the modeled SST after hour 90. The advection is important in the mixed layer heat balance during and subsequent to the passage of tropical cyclones (Price 1981; Jacob et al. 2000).
This contribution is particularly significant in the eddy region. The maximum cooling (and upwelling) is found in a ring around the core of the typhoon, which appears to start in the northeast corner of the typhoon where a wind-forced upslope flow may be involved. This initial cooling center appears to have been forced by the inertial dynamics of a fast wind-driven current up the shelfslope in the northeastern SCS. The downslope return flow can also create strong eddies by releasing potential energy, thus providing some significant mixing.

The thermocline displacement due to the typhoon-induced upwelling can be evaluated using the model results. Figure 9 further shows the time series temperature profile in the upper layer $(<300 \mathrm{~m})$ at different locations along latitude $20.5^{\circ} \mathrm{N}$. The temperature dropped to a depth of more than $150 \mathrm{~m}$ near the typhoon center $\left(\sim 119^{\circ} \mathrm{E}\right.$ in Fig. $8 \mathrm{c}$ af ter July 6 . The surface mixed layer kept cooling down and reached the minima at around July 8 . Since the thermocline was shallow (Fig. 2) prior to the passage of typhoon KaiTak, the deep water appeared to be upwelled to the surface near the typhoon center. This upwelling was also associated with strong mixed layer thickening, due to enhanced mixing and entrainment. The surface mixed layer not only thickened significantly but also mixed efficiently due to strong turbulence. The thermocline became much thinner due to the upwelled thermocline in the deeper layer. This mixed layer thickening (or thermocline thinning) occurred everywhere near the strong wind stress except for the far field at $116.5^{\circ} \mathrm{E}$ (Fig. 9a) as expected. Some previous studies have emphasized entrainment/mixing as the dominant term in the mixed layer heat budget (Jacob and Shay 2003). Jacob et al. (2000) suggested that entrainment/mixing at the base of the mixed layer generally accounts for a large portion of the cooling (75 - 90\%) based on observations. Inertial 
(a)
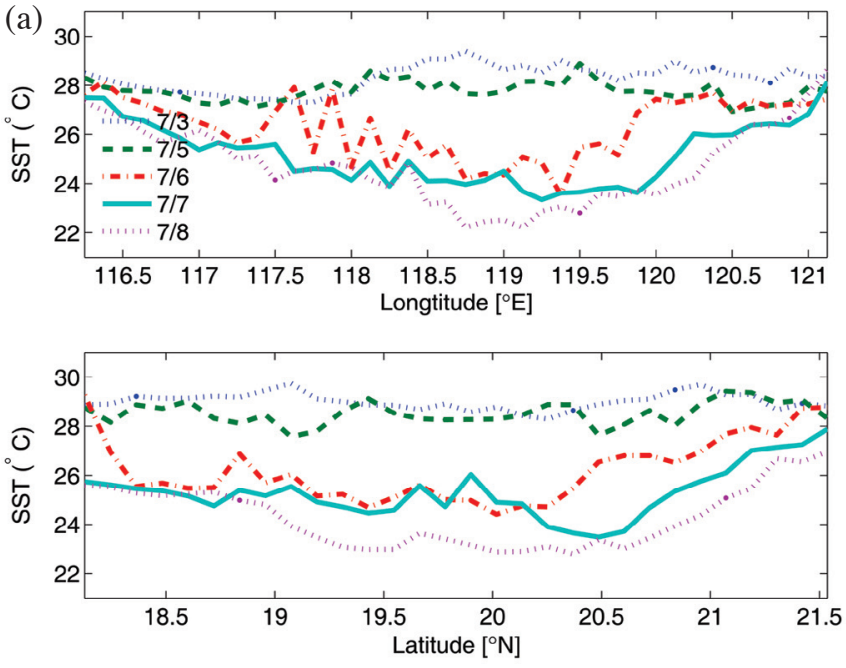

(b)

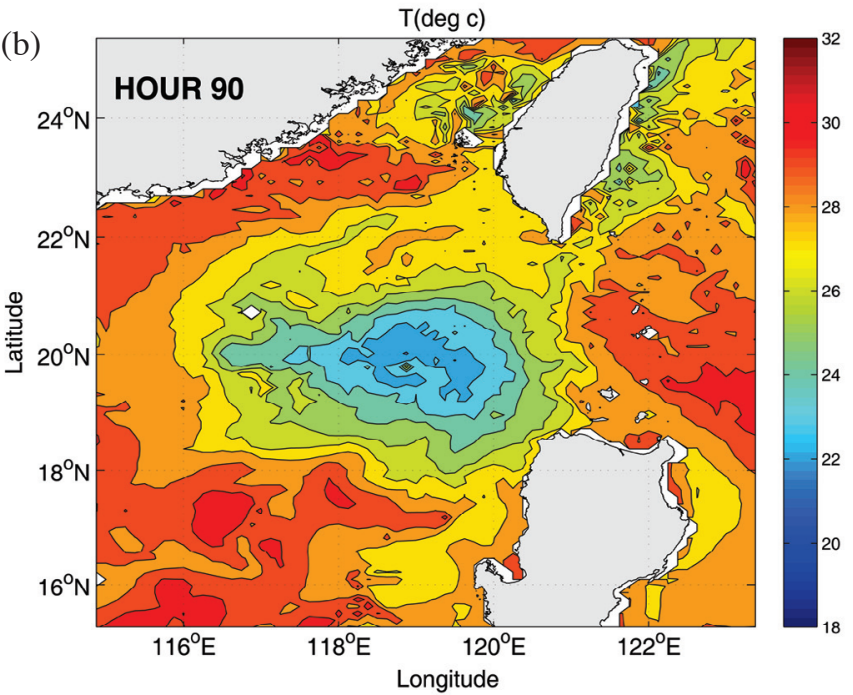

Fig. 8. (a) Horizontal SST distribution along longitude (top) and latitude (bottom). (b) Modeled SST distribution at hour 90.

(a) $2000 / 7$

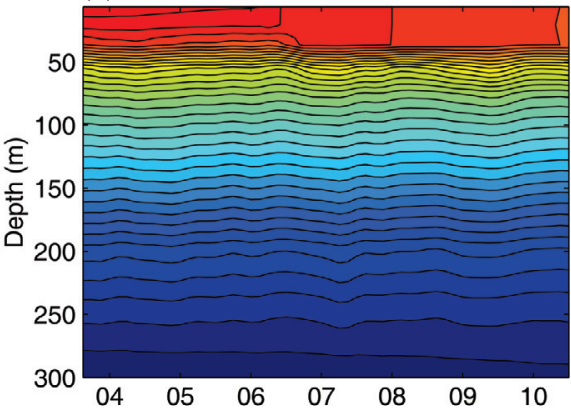

(c) $2000 / 7$

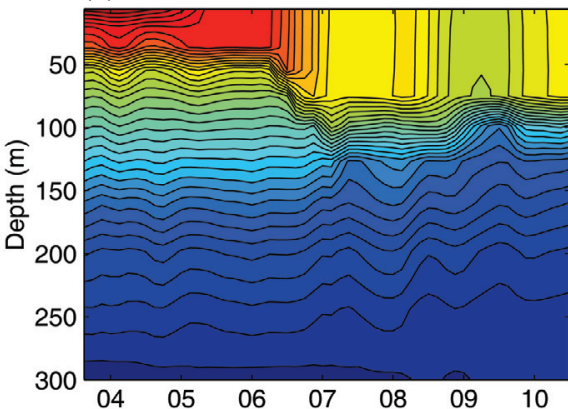

(b) $2000 / 7$

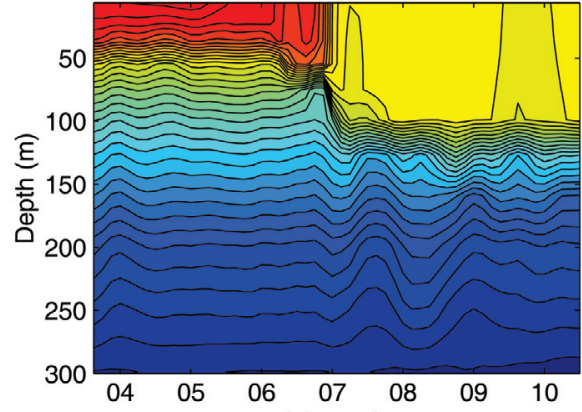

(d) $2000 / 7$

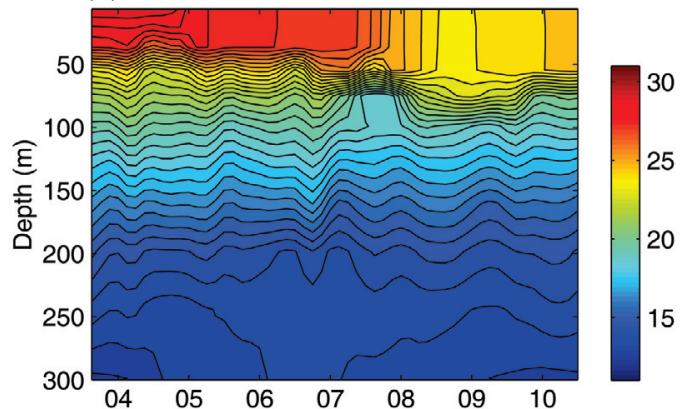

Fig. 9. Time-series temperature in the upper layer at different locations along latitude $20.5^{\circ} \mathrm{N}$. (a) $116.5^{\circ} \mathrm{E}$; (b) $118.5^{\circ} \mathrm{E}$; (c) $119^{\circ} \mathrm{E}$; and (d) $120.375^{\circ} \mathrm{E}$

oscillations were also identified from Fig. 9. Based on the model results, we estimated that the thermocline upwelled from depths of $70-100 \mathrm{~m}$ within the areas of maximum SST change.

What intensified the cooling at the center of the cold patch? The pre-conditioned shallow surface mixed layer could have played an important role. Qu et al. (2007) showed that the isothermal depth in the northern South China Sea can exceed $70 \mathrm{~m}$ in winter and fall below $20 \mathrm{~m}$ in summer near the continental slope south of China, based on the
World Ocean Database 2001 (WOD01). Consistent with our observations in Fig. 2, the monthly mean isothermal depth was at around $30-35 \mathrm{~m}$ in July where typhoon Kai-Tak hovered ( $\mathrm{Qu}$ et al. 2007). The thermocline in that area is generally shallower during spring and summer. In the other extreme surface cooling event during the passage of typhoon Ling-Ling, the mean thermocline for the area of extreme cooling was of around 25 - $35 \mathrm{~m}$ (Qu et al. 2007). Apparently, the preconditioned shallow mixed layers contributed significantly to the extremely cool pool in both cases since 
the cold water below the thermocline was totally upwelled to the surface. In addition, the cooling area of typhoon LingLing was also associated with a locally pre-existing cyclonic gyre from the T/P derived geopotential anomaly, which appeared to be a sub-basin scale seasonal circulation driven by the winter monsoon (Shang et al. 2008). Maximum cooling was found at the gyre center where the thermocline was much shallower than usual condition ( $\sim 30 \mathrm{~m}$ compared to the more typical $50-100 \mathrm{~m}$ in winter). The pre-conditioned shallow mixed layer favored more vigorous cooling. With much cooler water nearer the surface, less energy is needed to lift the deeper water to the surface, resulting in large and rapid surface cooling. Note that typhoon Kai-Tak was declared to be a category 2 typhoon whereas typhoon LingLing was classified as category 4.

The strong upwelling during the passage of typhoon Kai-Tak should also be associated with other upwelling mechanisms, so that waters below the thermocline could be effectively upwelled to the surface. Figure 10 shows the daily averaged vertical subsidence calculated at $45 \mathrm{~m}$ depth on July 7 (day 5); it shows strong vertical upwelling (negative subsidence is upward) near the cold pool when the typhoon hovered in the northeastern SCS. The averaged maximum vertical velocity reached $30 \mathrm{~m}^{\text {day }}{ }^{-1}$ near the typhoon center, indicating a very large amount of vertical convection. The thermocline slope in Fig. 9c shows that the instantaneous vertical velocity can be even larger. The continuous Ekman pumping during July $5-8$ due to the lingering tail of the typhoon is also enhanced by the topographical upwelling (Fig. 11). Figure 11 shows the bottom currents flowing along the topography. The isobaths are also plotted in Fig. 11.Very strong alongshore currents occurred near the Philippine coastal shelf. A quasi-cyclonic eddy associated with large upward motion can be observed near the center of the cold pool. This near bottom cyclonic eddy was col- located with the typhoon center, and was strengthened by the bottom bathymetry. This deep eddy, resulting from the bathymetry steering, may have enhanced the strong upwelling locally. Similar bathymetry or deep canyon enhanced upwelling can also be found in Monterey Bay, USA (e.g., Tseng et al. 2005; Tseng and Breaker 2007). This enhancement is usually associated with strong cyclonic eddy.

These features are also consistent with other earlier observations. In Hurricane Ivan (September, 2004), SSH data showed pre-existing cyclonic circulation in the areas where extreme cooling occurred. North of the warm core eddy, maximum cooling occurred 40 to $90 \mathrm{~km}$ east of Ivan's track in the area of maximum SSH change. Its location agreed well with the results of Price (1981), who found that maximum cooling for rapidly moving hurricanes usually occurs $30-150 \mathrm{~km}$ to the right of the track. However,

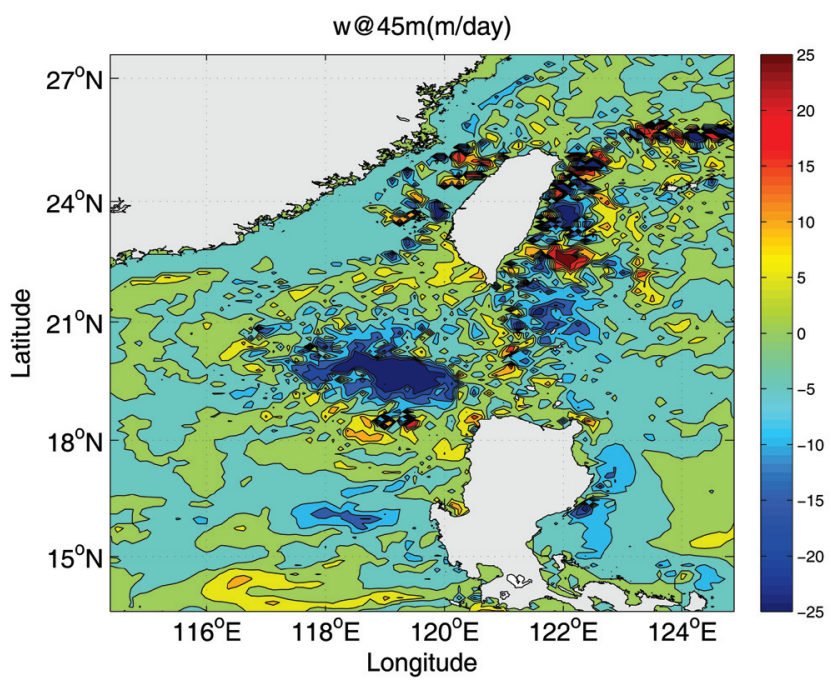

Fig. 10. Daily averaged vertical velocity at a $45 \mathrm{~m}$ depth for day $5(7 / 7)$ (a)

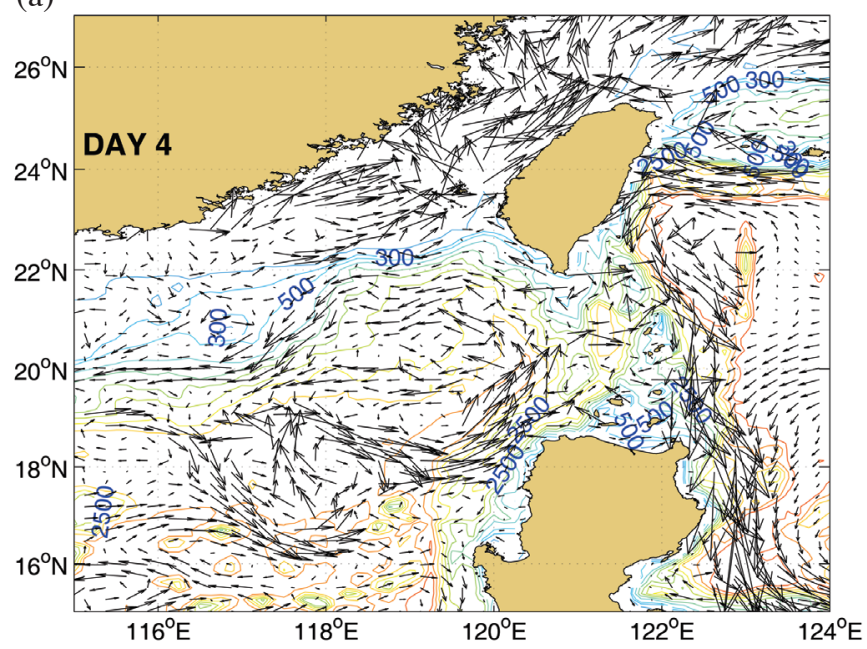

(b)

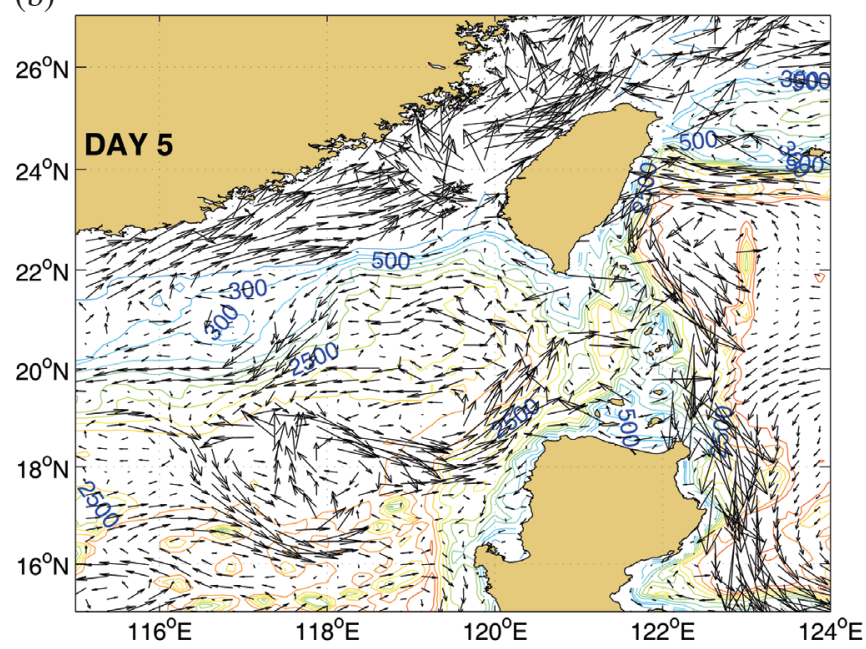

Fig. 11. Daily averaged bottom current vectors just above the bottom cell for day 4 (a) and day 5 (b). The bathymetry is colored as contours. 
another maximum cooling also occurred within the area of cyclonic circulation south of the warm core eddy, closest to Ivan's track. This large cooling effect extended further west than would have been expected based on previous research. Our results suggest that the observed extreme cooling was possibly due to strong upwelling caused by the bathymetric steering.

\section{SUMMARY}

In this paper, we illustrate an application of a multiple domain modeling development study using a simulation of the ocean response to typhoon Kai-Tak. An intense nonlinear mesoscale eddy was generated with a Rossby radius of O $(50-100 \mathrm{~km})$ horizontal scale in the northeastern SCS. Inertial oscillation was clearly observed. For the first few modeled days, advection dominated as the strong wind shear drove the mixed layer flows outward, away from the typhoon center, thus forcing upwelling from deep levels with correspondingly large upwelling velocities (> 30 $50 \mathrm{~m} \mathrm{day}^{-1}$ ). The surface mixed layer deepened as the thermocline rose and caused deeper convergence. The mixed layer and thermocline merged after July 6 , when the thermocline water mixed to the surface rapidly due to wind-generated turbulence. A SST drop more than $9^{\circ} \mathrm{C}$ was found in both observation and simulation. This significant SST drop resulted from the influence of a slow moving typhoon, initial stratification and bathymetry-induced upwelling in the region where the typhoon hovered.

Acknowledgements The authors acknowledge the computing resource of National Center for High Performance Computing, Taiwan. Comments from the anonymous reviewers are deeply appreciated. Financial support for this work was provided by National Science Council, Taiwan (grant NSC972628M002001). Dr. S. Jan was granted by Taiwan's National Applied Research Laboratories under grant 97-TORI-007.

\section{REFERENCES}

Chang, S. W. and R. A. Anthes, 1978: Numerical simulations of the ocean's nonlinear, baroclinic response to translating hurricanes. J. Phys. Oceanogr., 8, 468-480, doi: 10.1175/1520-0485(1978)008<0468:NSOTON>2. 0.CO;2. [Link]

Chen, Y. K., 2006: Typhoon-induced inertial motion in the South China Sea. Master Thesis, Institute of Oceanography, National Taiwan University, Taipei, Taiwan, 98 pp. (in Chinese)

Cubukcu, N., R. L. Pfeffer, and D. E. Dietrich, 2000: Simulation of the effects of bathymetry and land-sea contrasts on hurricane development using a coupled ocean-atmosphere model. J. Atmos. Sci., 57, 481-492, doi: 10.1175/1520-0469(2000)057<0481:SOTEOB >2 . 0.CO;2. [Link]

Dietrich, D. E., 1997: Application of a modified 'a' grid ocean model having reduced numerical dispersion to the Gulf of Mexico circulation. Dyn. Atmos. Oceans, 27, 201-217, doi: 10.1016/S0377-0265(97)00009-2. [Link]

Dietrich, D. E., A. Mehra, R. L. Haney, M. J. Bowman, and Y. H. Tseng, 2004a: Dissipation effects in North Atlantic Ocean modeling. Geophys. Res. Lett., 31, L05302, doi: 10.1029/2003GL019015. [Link]

Dietrich, D. E., R. L. Haney, V. Fernandez, S. Josey, and J. Tintore, 2004b: Air-sea fluxes based on observed annual cycle surface climatology and ocean model internal dynamics: A non-damping zero-phase-lag approach applied to the Mediterranean Sea. J. Mar. Syst., 52, 145-165, doi: 10.1016/j.jmarsys.2004.01.006. [Link]

Dietrich, D. E., Y. H. Tseng, S. Jan, P. Yau, C. Lin, and X. Wang, 2007: Modeled ocean response to Hurricane Katrina (extended abstract), The $16^{\text {th }}$ Conference on Atmospheric and Oceanic Fluid Dynamics, Santa Fe, New Mexico, 25-29, June.

Dietrich, D. E., Y. H. Tseng, R. Medina, S. A. Piacsek, M. Liste, M. Olabarrieta, M. J. Bowman, and A. Mehra, 2008: Mediterranean Overflow Water (MOW) simulation using a coupled multiple-grid Mediterranean Sea/ North Atlantic Ocean model. J. Geophys. Res., 113, C07027, doi: 10.1029/2006JC003914. [Link]

Emanuel, K. A., 1986: An air-sea interaction theory for tropical cyclones Part I: Steady-state maintenance. $J$. Atmos. Sci., 43, 585-605, doi: 10.1175/1520-0469(198 5)042<1062:FCITPO >2.0.CO;2. [Link]

Emanuel, K. A., 1999: Thermodynamic control of hurricane intensity. Nature, 401, 665-669, doi: 10.1038/44326. [Link]

Emanuel, K. A., 2001: Contribution of tropical cyclones to meridional heat transport by the oceans. J. Geophys. Res., 106, 14771-14781, doi: 10.1029/2000JD900641. [Link]

Gill, A. E., 1982: Atmosphere-Ocean Dynamics, Academic, New York, 622 pp.

Hellerman, S. and M. Rosenstein, 1983: Normal monthly wind stress over the world ocean with error estimates. J. Phys. Oceanogr., 13, 1093-1104, doi: 10.1175/1520 -0485(1983)013<1093:NMWSOT>2.0.CO;2. [Link]

Jacob, S. D. and L. K. Shay, 2003: The role of oceanic mesoscale features on the tropical cyclone-induced mixed layer response: A case study. J. Phys. Oceanogr., 33, 649-676, doi: 10.1175/1520-0485(2003)33<649:TRO $\mathrm{OMF}>2.0 . \mathrm{CO} ; 2$. [Link]

Jacob, S. D., L. K. Shay, and A. J. Mariano, 2000: The 3D oceanic mixed layer response to Hurricane Gilbert. $J$. Phys. Oceanogr., 14, 59-78.

Large, W. G. and S. Pond, 1981: Open ocean momentum 
flux measurements in moderate to strong winds. $J$. Phys. Oceanogr., 11, 324-336, doi: 10.1175/1520-048 5(1981)011<0324:OOMFMI>2.0.CO;2. [Link]

Levitus, S. and T. Boyer, 1994: World Ocean Atlas: 1994 Temperature, NOAA Atlas NESDIS 4, Diane Publishing Co., 150 pp.

Lin, I., W. T. Liu, C. C. Wu, G. T. F. Wong, C. Hu, Z. Chen, W. D. Liang, Y. Yang, and K. K. Liu, 2003: New evidence for enhanced ocean primary production triggered by tropical cyclone. Geophys. Res. Lett., 30, 1718, doi: 10.1029/2003GL017141. [Link]

Lin, I. I., C. C. Wu, K. A. Emanuel, I. H. Lee, C. R. Wu, and I. F. Pun, 2005: The interaction of Supertyphoon Maemi (2003) with a warm ocean eddy. Mon. Weather Rev., 133, 2635-2649, doi: 10.1175/MWR3005.1. [Link]

Lin, I. I., C. C. Wu, I. F. Pun, and D. S. Ko, 2008: Upperocean thermal structure and the Western North Pacific category 5 typhoons. Part I: Ocean features and the category 5 typhoons' intensification. Mon. Weather Rev., 136, 3288-3306, doi: 10.1175/2008MWR2277.1. [Link]

Lin, I. I., I. F. Pun, and C. C. Wu, 2009a: Upper-ocean thermal structure and the Western North Pacific category-5 typhoons. Part II: Dependence on translation speed. Mon. Weather Rev., 137, 3744-3757, doi: 10.1175/2009MWR2713.1. [Link]

Lin, I. I., C. H. Chen, I. F. Pun, W. T. Liu, and C. C. Wu, 2009b: Warm ocean anomaly, air sea fluxes, and the rapid intensification of tropical cyclone Nargis (2008). Geophys. Res. Lett., 36, L03817, doi: 10.1029/2008GL035815. [Link]

Moon, I. J., I. Ginis, T. Hara, and B. Thomas, 2007: A Physics-based parameterization of air-sea momentum flux at high wind speeds and its impact on hurricane intensity predictions. Mon. Weather Rev., 135, 2869-2878, doi: 10.1175/MWR3432.1. [Link]

Moon, I. J., I. Ginis, and T. Hara, 2008: Impact of the reduced drag coefficient on ocean wave modeling under hurricane conditions. Mon. Weather Rev., 136, $1217-$ 1223, doi: 10.1175/2007MWR2131.1. [Link]

Oey, L. Y., T. Ezer, D. P. Wang, X. Q. Yin, and S. J. Fan, 2006: Loop Current warming by Hurricane Wilma. Geophys. Res. Lett., 33, L08613, doi: 10.1029/2006GL025873. [Link]

Oey, L. Y., T. Ezer, D. P. Wang, X. Q. Yin, and S. J. Fan, 2007: Hurricane-induced motions and interaction with ocean currents. Cont. Shelf Res., 27, 1249-1263, doi: 10.1016/j.csr.2007.01.008. [Link]

Pacanowski, R. C. and S. G. H. Philander, 1981: Parameterization of vertical mixing in numerical models of tropical oceans. J. Phys. Oceanogr., 30, 1069-1082.

Powell, M. D., P. J. Vichery, and T. Reinhold, 2003: Reduced drag coefficient for high wind speeds in tropi- cal cyclones. Nature, 422, 279-283, doi: 10.1038/nature01481. [Link]

Prasad, T. G. and P. J. Hogan, 2007: Upper-ocean response to Hurricane Ivan in a $1 / 25^{\circ}$ nested Gulf of Mexico HYCOM. J. Geophys. Res., 112, C04013, doi: 10.1029/2006JC003695. [Link]

Price, J. F., 1981: Upper ocean response to a hurricane. J. Phys. Oceanogr., 11, 153-175, doi: 10.1175/1520-048 5(1981)011<0153:UORTAH>2.0.CO;2. [Link]

Price, J. F., T. B. Sanford, and G. Z. Forristall, 1994: Forced stage response to a moving hurricane. J. Phys. Oceanogr., 24, 233-260, doi: 10.1175/1520-0485(1994)024< 0233:FSRTAM>2.0.CO;2. [Link]

Qu, T., Y. Du, J. Gan, and D. Wang, 2007: Mean seasonal cycle of isothermal depth in the South China Sea. J. Geophys. Res., 112, C02020, doi: 10.1029/2006JC003583. [Link]

Shang, S. L., L. Li, F. Sun, J. Wu, C. Hu, D. Chen, X. Ning, Y. Qiu, C. Zhang, and S. Shang, 2008: Changes of temperature and bio-optical properties in the South China Sea in response to typhoon Lingling, 2001. Geophys. Res. Lett., 35, L10602, doi: 10.1029/2008GL033502. [Link]

Shay, L. K., R. L. Elsberry, and P. G. Black, 1989: Vertical structure of the ocean current response to a hurricane. J. Phys. Oceanogr., 19, 649-669, doi: 10.1175/1520-0 485(1989)019<0649:VSOTOC>2.0.CO;2. [Link]

Shay, L. K., G. J. Goni, and P. G. Black, 2000: Effects of a warm oceanic feature on Hurricane Opal. Mon. Weather Rev., 128, 1366-1383, doi: 10.1175/1520-0493(200 0)128<1366:EOAWOF>2.0.CO;2. [Link]

Sheng, J., X. Zhai, and R. J. Greatbatch, 2006: Numerical study of the storm-induced circulation on the Scotian Shelf during Hurricane Juan using a nested-grid ocean model. Prog. Oceanogr., 70, 233-254, doi: 10.1016/j. pocean.2005.07.007. [Link]

Sheng, J., L. Wang, S. Androfouot, C. Hu, B. G. Hatcher, F. E. Muller-Karger, B. Kjerfve, W. D. Heyman, and B. Yang, 2007: Upper ocean response of the Mesoamerican Barrier Reef System to Hurricane Mitch and coastal freshwater inputs: A study using Sea-viewing Wide Field-of-view Sensor (SeaWiFS) ocean color data and a nested-grid ocean circulation model. J. Geophys. Res., 112, C07016, doi: 10.1029/2006JC003900. [Link]

Tsai, Y., C. S. Chern, and J. Wang, 2008: The upper ocean response to a moving typhoon. J. Oceanogr., 64, 115130, doi: 10.1007/s10872-008-0009-1. [Link]

Tseng, Y. H., 2008: High-order essentially local extremum diminishing schemes for environmental flows. Int. $J$. Numer. Methods Fluids, 58, 213-235, doi: 10.1002/fld. 1725. [Link]

Tseng, Y. H. and D. E. Dietrich, 2006: Entrainment and transport in idealized three-dimensional idealized grav- 
ity current simulation. J. Atmos. Ocean. Technol., 23, 1249-1269, doi: 10.1175/JTECH1915.1. [Link]

Tseng, Y. H. and L. C. Breaker, 2007: Nonhydrostatic simulations of the regional circulation in the Monterey Bay area. J. Geophys. Res., 112, C12017, doi: 10.1029/2007 JC004093. [Link]

Tseng, Y. H., J. H. Ferziger, and D. E. Dietrich, 2005: Regional circulation of the Monterey Bay region: Hydrostatic versus nonhydrostatic modeling. J. Geophys. Res., 110, C09015, doi: 10.1029/2003JC002153. [Link]

Wu, C. C., C. Y. Lee, and I. I. Lin, 2007: The effect of the ocean eddy on tropical cyclone intensity. J. Atmos. Sci., 64, 3562-3578, doi: 10.1175/JAS4051.1. [Link]

Wu, C. R., Y. L. Chang, L. Y. Oey, C. W. J. Chang, and Y. C. Hsin, 2008: Air-sea interaction between tropical cyclone Nari and Kuroshio. Geophys. Res. Lett., 35, L12605, doi: 10.1029/2008GL033942. [Link]

Zedler, S. E., T. D. Dickey, J. F. Doney, J. F. Price, X. Yu, and G. L. Mellor, 2002: Analyses and simulations of the upper ocean's response to Hurricane Felix at the Bermuda Testbed Mooring site: 13-23 August 1995. J. Geophys. Res., 107, 3232, doi: 10.1029/2001JC000969. [Link] 